\title{
Customer Experience Modeling: Designing Interactions for Service Systems
}

\author{
Jorge Teixeira $^{1}$, Lia Patrício ${ }^{2}$, Nuno J. Nunes ${ }^{1}$, and Leonel Nóbrega ${ }^{1}$ \\ ${ }^{1}$ Madeira Interactive Technologies Institute, \\ University of Madeira, Portugal \\ jorgegrenha@m-iti.org, \{njn, Inobrega\}@uma.pt \\ ${ }^{2}$ College of Engineering, University of Porto, Portugal \\ lpatric@fe.up.pt
}

\begin{abstract}
Designers aspire to create engaging and desirable experiences. To that end they study users, aiming to better understand their preferences, ways of thinking and desired outcomes. In the service sector this task is more intricate as experiences encompass the whole customer journey, or the sequence of moments of interaction between customer and company. In services, one poorly designed interaction can severely compromise the overall experience. Despite experience holistic nature, current methods address its components separately, failing to provide an overall systematized picture. This paper presents Customer Experience Modeling, a novel multidisciplinary approach to systematize, represent and evaluate customer experiences to guide service and interaction design efforts. We illustrate this method with an application to a multimedia service provider built upon 17 interviews with service users.
\end{abstract}

Keywords: Customer Experience, User Experience, User Modeling, Service Design.

\section{Introduction}

Addressing experiences can be a daunting task. Experiences are unavoidable and ubiquitous, personal and subjective, and they are built from every contextual element in a given setting. Introduced by Pine and Gilmore [1] as an economic offering on its own, experience is nowadays discussed in interaction design $[2,3]$ and service design $[4,5]$. Both consider experience a desirable feature and aspire to achieve engaging ones $[5,6]$. For companies experience is consensually considered a source of sustainable competitive advantage [7, 8]. However, each field frames experience differently. Interaction Design considers users as the experience recipients and thus devotes its attention towards making products usable and agreeable to them [9]. This way user experience is viewed as an integrated offer of functional, or usability, benefits as well as emotional ones $[7,10]$. In fact, some consider user experience as a better aim for Interaction Design and HCI than usability due to the narrow range of the latter [6, 10]. On the other hand, service design is concerned over customers, encompassing not only physical artifacts but the entire orchestration of service components such as physical environment, employees and service delivery process. 
Whereas user experience necessarily involves an interaction, customer experience has been defined as the cognitive and affective outcomes of the customer's exposure or interaction with a company's people, processes, technologies, product, services, or other outputs [11]. Services do include products, or other interactive artifacts, but go far beyond them, being therefore more complex and difficult to design [12]. This study is purposively focused on customer experience as it aims to portray its holistic nature by encompassing every contact, direct and indirect with a service.

Existing methods already aim to handle the richness of experience data, albeit their focus is on its separate components. Personas depict representative users, service blueprints illustrate a service delivery process, use cases put forward a product, system or service intended functionalities, mood boards explore its emotional landscapes [13], to name a few. Experiences, however, are a combination of all aspects addressed by these methods and are perceived as a complex but unitary feeling [8]. As such, there is a lack of methods to handle experience as a holistic reality.

We introduce here Customer Experience Modeling (CEM), a method for interaction and service designers that supports the complexity inherent to service's customer experience. Leveraging contributions from well defined frameworks, concretely Human Activity Modeling [14], Goal-Oriented Analysis [15], and Multilevel Service Design [16] this method is able to systematize, represent and evaluate the several components that shape customer experiences .

\section{Conceptual Foundations of Customer Experience Modeling}

Models are abstract representations that weed out irrelevant details to focus on what is significant, explaining the operation and underlying concepts of systems that are too complex to be otherwise understood [17]. By using models to represent gathered knowledge we are able to synthesize and express it in a way that enhances communication between multiple stakeholders from different fields.

Models play an important role in interaction design as they help bridge the gap between problem and solution. According to the Analysis-Synthesis Bridge Model [18], the design process starts with observation and investigation of the current situation. Next, modeling is used to form a bridge between problem and solution, by helping interpret and systematize the understanding of the existing situation and explore new potential solutions. Finally, through an iterative process, idealized solutions are materialized into prototypes and ultimately finished forms.

CEM fits into this approach, offering a modeling framework that helps to represent and systematize gathered knowledge about customer experience and then shed this knowledge into interaction and service design efforts. However, capturing the complexity of experience required several contributions from different fields, namely Human Activity Modeling (HAM) [14] concepts and notation, Goal-Oriented Analysis' [15] softgoal concept and the three levels of experience from Multilevel Service Design (MSD) [16]. HAM gives the concepts and notation required to represent experience, the softgoals express desired characteristics to evaluate experience components and MSD provides a structure to systematize experience from an overall perspective to each single interaction. 


\subsection{Muldisciplinary Contributions}

Human Activity Modeling (HAM) is a systematic approach to represent activities, developed to succinctly capture and represent them and their context to support practicing designers [14]. HAM provides the necessary conceptual backbone and notation to model interactions and its context, a first step towards customer experience improvement. Beyer and Holtzblatt consider context the backbone for organizing a customer-centric design process [19]. HAM's theoretical support lies on Activity Theory, a philosophical and cross-disciplinary framework that considers human activities as basic units of analysis and sees them mediated by artifacts [14, 20]. HAM also provides a representation, called Participation Map, of the participants and their relationships with each other and with the artifacts involved in an activity. This diagram is included in CEM to depict the contextual elements related with customer experience. However, HAM does not accommodate evaluation tools and is a system-centric approach, thus it needs to be adapted and integrated with other approaches.

CEM aims not only to represent and systematize customer experiences, but also to evaluate them in order to guide service and interaction design efforts. To accomplish this we need to elicit and portray user's activities, and also the goals behind them. Goal-Oriented Analysis'softgoal concept addresses experience subjective nature by accommodating partial, or intermediate states of satisfaction [15]. By introducing softgoals we can effectively evaluate each performed activity according to the desired requirements, thus detecting gaps or flaws susceptible to be addressed when designing service interactions. This way, it is possible to concentrate efforts on the most critical activities, modifying them or introducing new ones to enhance experiences. The concept of Softgoal is useful to represent experience factors, however they need to be complemented with models more focused on the service setting.

Multilevel Service Design (MSD) is a multidisciplinary method for designing services with embedded contributions from service development, interaction design and service design [16]. MSD proposes three levels of customer experience; value constellation experience, service experience and service encounter experience. Value constellation experience results from interactions between the customer and all service organizations needed to perform a given customer activity. Therefore it is not centered on a company's offering, but instead on the customer's activity and what services he uses to accomplish them. Service experience level shows how experience is shaped from different encounters with a single company, and which factors enable or inhibit the desired experience. Finally, service encounter experience level provides all relevant details for a single interaction, a specific encounter with the service, through a single channel. MSD offers a multilevel view of customer experience which already addresses some of its complexity. However, its representation still needs to evolve to provide a richer and concrete understanding of customer experience.

Customer experience can be represented, systematized and evaluated by integrating these multidisciplinary contributions. The next section presents CEM and shows how it was used to study a multimedia service provider customer's experience. 


\section{Customer Experience Modeling (CEM)}

Representing the richness and complexity of customer experience requires an abstraction, a model with which the stakeholders can relate and use to communicate. Conceptually founded on an adapted customer-centric HAM [14], we followed the three levels of service design [16] and introduced the softgoal concept [15] to develop CEM, a multidisciplinary, multilevel approach, that captures and evaluates relevant features of customer experiences to support interaction and service designers.

\subsection{Concepts, Notation and Structure}

Since our objective is to guide interaction design and service design efforts from a broader contextual perspective to a single interaction we adopted the three hierarchical levels of MSD: value constellation experience, service experience and service encounter experience. Considering these three levels of service design enables us to trace each interaction from a single encounter to the overall value offering. HAM is the method's conceptual and notational foundation. However, we conducted a major adaptation in its perspective, as we regard it as customer-centric instead of system-centric. Therefore, the definition of each concept was altered to reflect this focus, as shown in Table 1.

Table 1. Adapted Notation for Customer Experience Modeling

\begin{tabular}{|c|c|c|}
\hline Symbol & Name & Description \\
\hline & Artifact & Any artifact employed within an activity [14]. \\
\hline & $\begin{array}{l}\text { System } \\
\text { Actor }\end{array}$ & $\begin{array}{l}\text { Non human system (software or hardware) interacting with } \\
\text { the customer. }\end{array}$ \\
\hline & Role & Relationship between an actor and the customer. \\
\hline & Actor & $\begin{array}{l}\text { Activity participant interacting with the customer (or the } \\
\text { customer himself). }\end{array}$ \\
\hline & Softgoal & $\begin{array}{l}\text { Condition in the world which the actor would like to } \\
\text { achieve, but unlike in the concept of (hard-) goal, the } \\
\text { criterion for the condition being achieved is not sharply } \\
\text { defined a priori, and is subject to interpretation [21] }\end{array}$ \\
\hline Activity & Activity & $\begin{array}{l}\text { Collection of actions or tasks undertaken for some purpose } \\
\qquad[14]\end{array}$ \\
\hline Action & Action & Action by a customer for some goal within an activity \\
\hline
\end{tabular}

To evaluate each activity and contextual component at different experience levels we introduced the softgoal concept $[15,21]$. Figure 1 gives a generic view of CEM, showing how all these elements fit together. 




Fig. 1. Customer Experience Modeling generic view

\subsection{Application of Customer Experience Modeling to a Multimedia Service Provider}

CEM was put forth as part of a project to redesign the service offering of a large portuguese multimedia service provider. Its service offerings include cable TV, highspeed internet, phones and several video on-demand channels. The project involved a multidisciplinary team of business specialists, designers, and software engineers through an end-to-end effort, from studying customer experience, to implementing design chances in operational and system level. Customer experience data and the multidisciplinary team provided a fruitful ground for CEM's development. For this research, we interviewed seventeen customers and conducted a qualitative analysis of customer experiences, using grounded theory methodology [22]. The CEM for this multimedia service provider is shown in Figure 2. As we can see each level includes activities on the left, softgoals at the middle and, on the right, contextual elements represented by a participation map centered around the customer.

In the first level we are representing the value constellation experience, as such the participation map includes offerings, and consequent interactions, of many service providers. When crossing to the lower level, we select one of these service provider 
offerings and begin studying the customer's experience with it. In the bottom, the service encounter experience level is centered on a sole activity and the actions it comprises. At this level our focus is on very concrete interactions and, as before, softgoals and the participation map should reflect the concerns of the actions at hand.

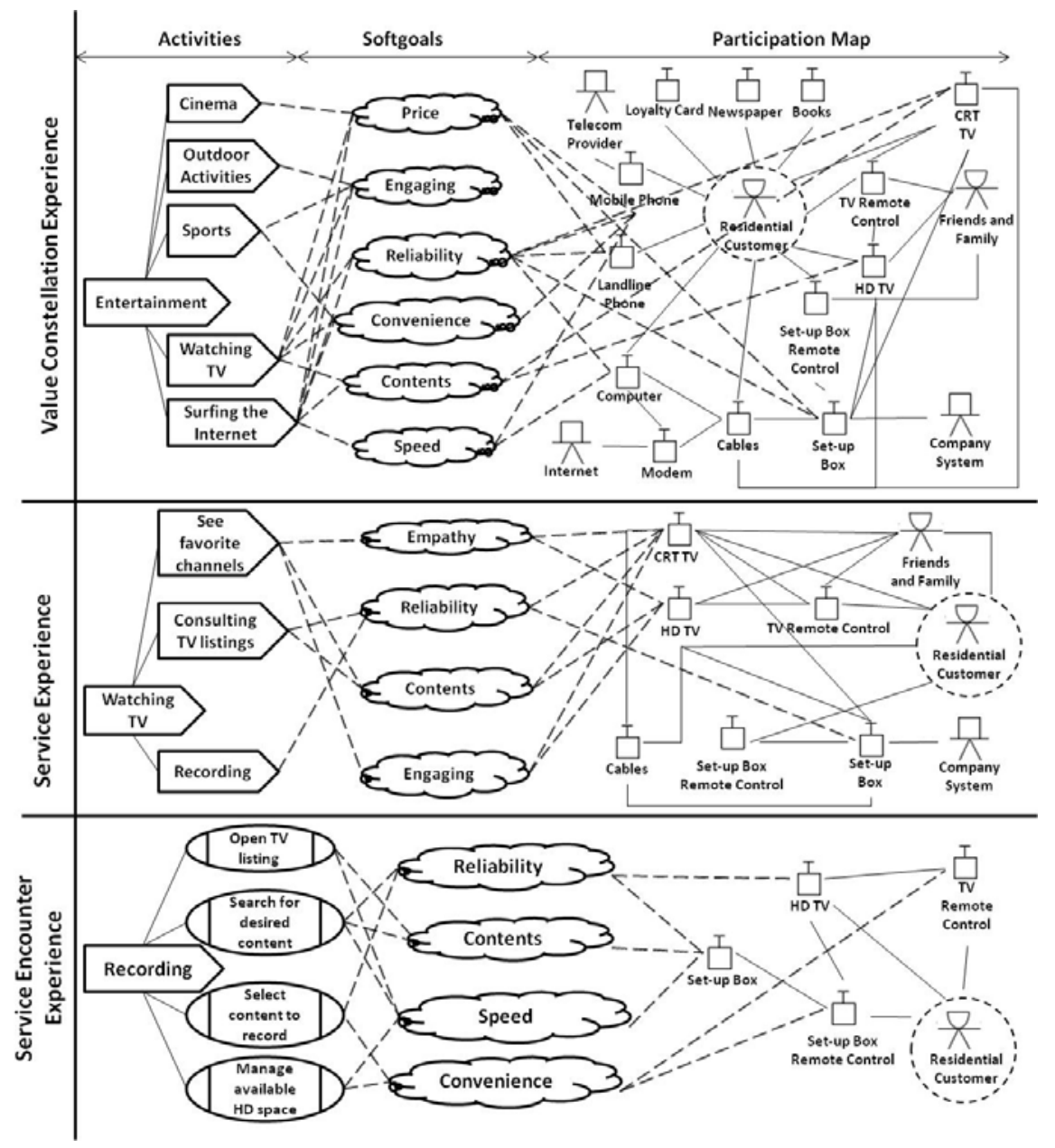

Fig. 2. Customer Experience Modeling for a Multimedia service provider

The participation map systematizes contextual elements related with activities within the same level. Therefore, the customer is surrounded by artifacts, systems and people with which he/she interacts. For that reason we have wrapped him within an interaction line, meaning that whenever he/she crosses that line he/she interacts with the immediate context around him. Every single interaction can be accounted for and related with softgoals for evaluation. 
By analyzing the service provider's business model we selected the overall customer activity Entertainment. This overall customer activity is represented at the first level and is then divided into several more concrete activities, and connected to relevant softgoals. These softgoals represent the desired qualities, as expressed by the customers, of the activities and contextual elements. As we cross from one level to another, each activity partition reflects a new setting where the relative importance of softgoals is prone to change. We depict the most relevant softgoals for each level to give designers a granular and adapted view of experience for each activity. So, the first level shows that for Entertainment, customers consider activities like Watching $T V$ or Surfing the Internet. In these activities they value Price, Engagement, Reliability, Convenience, Contents and Speed. These softgoals also characterize the contextual elements on the participation map such as Computer or Set-Up Box. Similar interpretation applies to the remainder levels.

In the end, we obtain a holistic representation of customer experience at its different levels, enabling interaction designers to trace each interaction from the corresponding overall activity. Considering Figure 2, the Recording activity must be reliable, fast, convenient and content-rich. Except for convenience, every other softgoals applies to the set-up box. By comparing with the level above we see that only customers with HD TV perform this activity. Also, for Watching TV customers concentrate the softgoals on TVs (CRT and HD), which is not supplied by the company. We conclude that a crucial artifact for customer experience isn't under company control. Both interaction and service designers can improve experience based on this knowledge.

\section{Conclusion}

CEM is a multidisciplinary method to represent, systematize and evaluate customer experience. It follows a customer-centric, multilevel approach to envision experience as seen from customer's eyes, with multiple service providers shaping the value constellation experience, and zooming to each service experience, and each service encounter experience. By merging contributions from different fields, such as interaction design, requirements engineering and service design. CEM supports design efforts and provides useful guidance to improve customer experiences.

\section{References}

[1] Pine II, B.J., Gilmore, J.H.: Welcome to the experience economy. Harvard Business Review 76, 97 (1998)

[2] Forlizzi, J., Battarbee, K.: Understanding Experience in Interactive Systems. HumanComputer Interaction Institute (2004)

[3] Marcus, A.: The Cult of Cute: The Challenge of User Experience Design. Interactions 9(6), 29-33 (2002)

[4] Patrício, L., et al.: Designing Multi-Interface Service Experiences: The Service Experience Blueprint. Journal of Service Research 10, 318-334 (2008)

[5] Zomerdijk, L., Voss, C.: Service Design for Experience-Centric Services. Journal of Service Research 13, 67-82 (2010) 
[6] Law, E.L.C., et al.: Understanding, Scoping and Defining User experience: A Survey Approach. In: CHI -Conference-, vol. 2, pp. 719-728 (2009)

[7] Berry, L.L., et al.: Managing the Total Customer Experience. MIT Sloan Management Review 43, 85-90 (2002)

[8] Gentile, C., et al.: How to Sustain the Customer Experience: an overview of experience components that co-create value with the customer. European Management Journal 25, 395-410 (2007)

[9] Preece, J., et al.: Interaction design: beyond human-computer interaction. J. Wiley \& Sons, New York (2002)

[10] Monk, A., et al.: Funology: Designing Enjoyment. In: CHI -Conference, pp. 924-926 (2002)

[11] Buttle, F.: Customer Relationship Management: Concepts and Technologies. Elsevier Ltd., Amsterdam (2009)

[12] Norman, D.A.: Living with complexity. MIT Press, Cambridge (2011)

[13] Saffer, D.: Designing for interaction. Pearson Education (distrib.), Berkeley (2010)

[14] Constantine, L.: Human Activity Modeling: Toward A Pragmatic Integration of Activity Theory and Usage-Centered Design. In: Human-Centered Software Engineering: Software Engineering Models, Patterns and Architectures for HCI, pp. 27-51. Springer, London (2009)

[15] Mylopoulos, J., et al.: From Object-Oriented to Goal-Oriented Requirements Analysis. Communications of the ACM 42, 31 (1999)

[16] Patrício, L., et al.: Multilevel Service Design: From Customer Value Constellation to Service Experience Blueprinting. Journal of Service Research 14, 180-200 (2011)

[17] Ludolph, F.: Model-Based User Interface Design: Successive Transformations of a Task/Object Model. In: Wood, L.E. (ed.) User Interface Design: Bridging the Gap from User Requirements to Design. CRC Press, Boca Raton (1998)

[18] Dubberly, H., et al.: The Analysis-Synthesis Bridge Model. Interactions 15, 57-61 (2008)

[19] Beyer, H., Holtzblatt, K.: Contextual design: defining customer-centered systems. Morgan Kaufmann, San Francisco (1998)

[20] Kaptelinin, V., Nardi, B.A.: Acting with technology: activity theory and interaction design. MIT Press, Cambridge (2006)

[21] Yu, E.S.K.: Modeling Strategic Relationships for Process Reengineering. In: Yu, E.S.K., et al. (eds.) Social Modeling for Requirements Engineering, pp. 11-152. MIT Press, Cambridge (2011)

[22] Charmaz, K.: Constructing grounded theory: a practical guide through qualitative analysis. Sage Publications, London (2006) 